\title{
Using of magnetic resonance enterography in the management of Crohn's disease of the small intestine: First year of experience
}

\author{
Juan L. Mendoza ${ }^{1}$, Yago González-Lama², Carlos Taxonera ${ }^{1}$, Cristina Suárez-Ferrer ${ }^{2}$, Fátima Matute ${ }^{3}$, \\ María I. Vera ${ }^{2}$, Natalia López-Palacios ${ }^{1}$, Pablo Rodríguez ${ }^{3}$, Marta Calvo², Ramiro Méndez ${ }^{3}$, Miguel \\ Pastrana ${ }^{4}$, Concepción González ${ }^{4}$, Raquel Lana ${ }^{1}$, Ricardo Rodríguez ${ }^{3}$ and Luis Abreu ${ }^{2}$
}

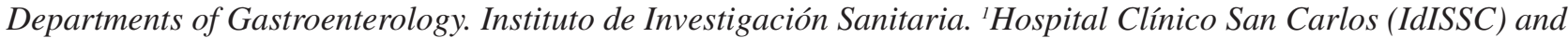
${ }^{2}$ Hospital Puerta de Hierro. Departments of Diagnostic Radiology. ${ }^{3}$ Hospital Clínico San Carlos and ${ }^{4}$ Hospital Puerta de Hierro. Madrid, Spain

\begin{abstract}
Objective: to describe the experience at two tertiary centres during the first year of use of magnetic resonance enterography (MRE) for the management of Crohn's disease (CD): indications and influence of the technique in clinical decision making.

Materials and methods: retrospective descriptive study in which patients who underwent MRE were included consecutively. Epidemiological and clinical data were collected from the patients, as well as the indication for the study and how it influenced clinical decision making in the 10 days following the radiological study.

Results: 24 MREs were performed in suspected CD and 126 known CD; partial bowel obstruction in 53 patients (42\%), monitoring of medical treatment in $34(27 \%)$, due to incomplete ileocolonoscopy in $16(13 \%)$, extension study of the small intestine in $15(12 \%)$ and suspected complicated CD in 8 patients (6\%). The MRE influenced in a change in treatment in $83(55.3 \%)$ patients: $16(10.7 \%)$ started with immunosuppressants, 41 (27.3\%) with antiTNF $\alpha$ were started on or switched, 15 (10\%) were ordered surgery and in $3(2 \%)$ changed from combined therapy to monotherapy. The MRE had less influence on clinical decision making in the group in which the indication was suspected CD $(p<0.05)$.

Conclusions: the use of MRE helped on decision making in more than half of patients, especially with regards to decisions related to the use of biological therapies and the indication for surgery. MRE was less useful in suspected CD patients
\end{abstract}

Key words: Crohn's disease. Enterography. Magnetic resonance. Diagnostic.

\section{INTRODUCTION}

Crohn's disease (CD) is characterised by a transmural inflammatory process of the intestine that may affect the entire gastrointestinal tract segmentally. CD lesions are

\footnotetext{
Received: 25-06-2012

Accepted: $18-10-2012$
}

Correspondence: Juan L. Mendoza. Department of Gastroenterology. Hospital Clínico San Carlos. C/ Martín Lagos, s/n. 28040 Madrid, Spain

e-mail: jmendozah@meditex.es highly variable; ulceration of the mucosa, oedema and thickening of the intestinal wall, fistulas, fibrotic stenosis, peritoneal lymphadenopathy and involvement of the mesenteric fat (1). Therefore, endoscopic and radiologic studies are necessary in order to properly characterise its extent and the intraluminal and extraluminal changes that are seen in $\mathrm{CD}$. The endoscopic procedures allow the mucosa of the gastrointestinal tract to be seen, but they cannot visualise the transmural or extra-intestinal involvement that is present in CD.

Small-Bowel Follow-Through (SBFT) is the classic diagnostic method used to evaluate small intestine involvement (2). Studies $(3,4)$ have shown that SBFT is less accurate than other radiologic techniques to detect the presence of active $\mathrm{CD}$ in the small intestine. Technological advances have led to the growing use of contrast ultrasound, computed tomography (CT) and magnetic resonance enterography (MRE) in the study of the $\mathrm{CD}$ in the small intestine, to the point that in the last consensus of the European Crohn's and Colitis Organisation (ECCO) $(5,6)$, enterography by MR and CT are the imaging techniques recommended to determine the extent of $\mathrm{CD}$ in the small intestine. MR and CT enterography are the most precise techniques for detecting intestinal and extra-intestinal involvement in penetrating lesions of the intestine in $\mathrm{CD}$ (5). The absence of radiation makes MRE the study of choice, especially in young patients who will require repeated studies $(5,6)$.

However, incorporating MRE into clinical practice requires an unavoidable learning curve: The radiologist who interprets the study must be familiar with the pathology and know what information is better for the gastroenterol-

Mendoza JL, González-Lama Y, Taxonera C, Suárez-Ferrer C, Matute F, Vera MI, López-Palacios N, Rodríguez P, Calvo M, Méndez R, Pastrana M, González C, Lana R, Rodríguez R, Abreu $L$. Using of magnetic resonance enterography in the management of Crohn's disease of the small intestine: First year of experience. Rev Esp Enferm Dig 2012;104:578-583. 
ogist; and the gastroenterologist must learn exactly what to expect from this diagnostic procedure. Definitively, beyond the different tasks that will evaluate the reliability and other characteristics of the technique, an audit in real clinical practice is necessary in order to understand precisely what the role it can play in the current management of patients with CD.

The purpose of this study is to describe the experience of two reference centres during the first year of use of MRE for the management of $\mathrm{CD}$, especially with regards to the indications, results and influence of the technique on clinical decision making.

\section{MATERIALS AND METHODS}

\section{Patients}

This is a retrospective descriptive study that included all patients who underwent MRE consecutively between April 2010 and April 2011 in two tertiary care centres with specialised units in the management of CD. Epidemiological and clinical data were collected, as well as the indications for the study, the radiological findings and, finally, how MRE influenced clinical decision making.

\section{Indications for MRE}

The indications made by clinicians to request the MRE study were classified in two groups: 1) Suspected CD, when clinical, laboratory and other radiological studies suggest a diagnosis of $\mathrm{CD}$, without a conclusive endoscopic study; and 2) the patient with known CD, the indications were subdivided into: a) Patients with clinical findings suggestive of partial bowel obstruction (predominantly nausea, vomiting, a feeling of abdominal distention and abdominal pain); b) suspected penetrating complications of CD (perforation, abscess and fistulas); c) disease extension study in the small intestine in patients with known CD; d) monitoring of therapeutic response in patients with medical treatments; and e) evaluation of clinical activity in patients in whom intubation of the small intestine with ileoscopy was not possible.

\section{MRE technique}

The studies were performed with a 1.5 Tesla MRE system (HDx; GE Medical Systems, Milwaukee, Wis. ${ }^{\mathrm{TM}}$ ) with a surface antenna that allows for the study of the entire abdomen and pelvis on the same study. In order to reduce intestinal peristalsis, $1 \mathrm{mg}$ of subcutaneous glucagon was used, $0.5 \mathrm{mg}$ at the start of the study and $0.5 \mathrm{mg}$ immediately before administering IV contrast. For distention of the ileum, 1.5 L of oral $5 \%$ mannitol was administered 45 minutes before the study. Afterwards, axial and coronal FIESTA pulse sequences were performed, as well as axial and coronal SSFSE FATSAT, detecting the involved or suspicious segments, completed according to a specific evaluation of each case with FIESTA pulse sequences in $3 \mathrm{~mm}$ slices over the area of study, with cholangiographic sequences for better visualisation of fistulous tracts.

The study was terminated with dynamic LAVA acquisition (at 30 seconds, 60 seconds, 3 minutes and 7 minutes) following administration of gadolinium contrast $(0.1$ $\mathrm{mmol} / \mathrm{kg}$; gadoterate dimeglumine, Dotarem ${ }^{\circledR}$, Guerbet, France $^{\mathrm{R}}$ ) in coronal projections with delayed LAVA acquisition in the coronal plane. The mean study time was approximately 35 minutes.

\section{Radiologic findings}

The following were evaluated: a) Wall thickening of the small intestine ( $\mathrm{mm})$; b) contrast enhancement of the wall after gadolinium infusion; c) prestenotic dilation $(>3 \mathrm{~cm})$; and $\mathrm{d}$ ) the existence of ulcers (defined as the presence of deep depressions in the surface of the mucosa). The mesenteric findings that were evaluated were: a) Hypertrophy of the mesenteric fat; b) hyperaemia; and c) the presence of lymphadenopathies. The extra-intestinal findings were classified as tracts, fistulas, phlegmons and intra-abdominal abscesses.

\section{Influence on clinical decision making}

The medical charts were reviewed and the clinical decisions taken in the 10 days following the MRE were recorded. Findings were classified as no when the patient's clinical management was not modified following the MRE and yes when medical treatment was modified or surgery was indicated.

\section{Statistical analysis}

The data were included in an Access database. The descriptive analysis included demographic, clinical, radiological and subsequent decision making data. Qualitative variables were expressed in absolute value and percentage. We compared the influence of MRE in clinical decision making between the two groups of indications (suspected CD vs. known CD) by the chi-square test, considered statistically significant at $\mathrm{p}<0.05$.

The study was approved by the ethics committees of both hospitals and all patients gave their consent to participate in the study.

\section{RESULTS}

In total, $150 \mathrm{MREs}$ were performed. The characteristics of the patients included in the study is described in table I. 
The mean time between the MRE and clinical decision making was 4 days (range 1-10). The indications and the influence on the clinical management of patients are described in table II.

The group of suspected CD was the 24 patients. MRE did not reveal any findings or was limited to confirming findings obtained by other radiological studies in $2 / 3$ of cases. In 7 patients, the findings obtained that were compatible with a diagnosis of $\mathrm{CD}$ led to starting medical treatment with corticosteroids. In 1 patient, the presence of a perforation made surgical treatment necessary.

The group of known CD was the 126 patients. The indication more frequent for MRE was the presence of clinical findings compatible with partial bowel obstruction $(n=53$

Table I. Phenotypic characteristics of the individuals included in the study with suspected or diagnosed Crohn's disease (CD) who underwent magnetic resonance enterography (MRE)

\begin{tabular}{|c|c|}
\hline CD phenotype & $n=150$ patients \\
\hline \multicolumn{2}{|l|}{ Gender } \\
\hline Male, n (\%) & $77(51.3 \%)$ \\
\hline Female, n (\%) & $73(48.7 \%)$ \\
\hline Age when performed, mean [range] years & $41[15-80]$ \\
\hline Diagnosis of $C D, n(\%)$ & $126(84 \%)$ \\
\hline Suspected CD, n (\%) & $24(16 \%)$ \\
\hline \multicolumn{2}{|l|}{ Age at diagnosis } \\
\hline Less than 16 years, n (\%) & $7(4.6 \%)$ \\
\hline $16-40$ years, $n(\%)$ & $98(65.4 \%)$ \\
\hline Over 40 years, $\mathrm{n}(\%)$ & $45(30 \%)$ \\
\hline \multicolumn{2}{|l|}{ CD location } \\
\hline Small intestine, n (\%) & $53(35.3 \%)$ \\
\hline Colon, n (\%) & $24(16 \%)$ \\
\hline Small intestine and colon, n (\%) & $45(30 \%)$ \\
\hline Upper gastrointestinal tract, $\mathrm{n}(\%)$ & $25(16.7 \%)$ \\
\hline \multicolumn{2}{|l|}{ CD behavior } \\
\hline Inflammatory, n (\%) & $77(51.3 \%)$ \\
\hline Stenosing, n (\%) & $27(18 \%)$ \\
\hline Penetrating, n (\%) & $46(30.7 \%)$ \\
\hline Perianal disease, n (\%) & $36(24 \%)$ \\
\hline Disease progression time, mean [range] years & $4[0-15$ years $]$ \\
\hline History of surgical intervention, n (\%) & $41(27 \%)$ \\
\hline \multicolumn{2}{|l|}{ Current treatments } \\
\hline None, n (\%) & $28(18.7 \%)$ \\
\hline Corticosteroids, n (\%) & $32(21.3 \%)$ \\
\hline Immunosuppressants, n (\%) & $79(52.7 \%)$ \\
\hline Anti-TNF $\alpha, n(\%)$ & $31(20.7 \%)$ \\
\hline
\end{tabular}

patients, 42\%). Clinical management was changed in a high percentage $(78 \%)$ of these patients. Medical treatment was intensified in 29 patients due to the predominance of inflammatory activity. Surgery was indicated in 9 patients immediately after undergoing MRE ( 8 due to the presence of stenosis in the small intestine predominated by fibrotic changes and in 1 patient when the presence of adhesions was identified as the cause of symptoms).

The second most frequent indication was for monitoring medical treatment $(\mathrm{n}=34$ patients, $27 \%)$. In this group of patients, the findings obtained on MRE did not modify the clinical approach, confirming adequate progress with the treatment given in more than half of patients (53\%). In 16 patients (47\%), MRE led to a change in the approach. Medical treatment was intensified in 10 patients. In 3 patients, disease complications secondary to surgical treatment were seen. In another 3 patients who were on combined therapy (anti-TNF $\alpha+$ immunosuppressants) and who were in clinical

Table II. Indication for MRE and repercussion on the clinical management of the $C D$ patient

\begin{tabular}{|c|c|c|}
\hline Indication & $\begin{array}{c}\text { Pacientes } n(\%) \\
n=150\end{array}$ & $\begin{array}{l}\text { Influence on } \\
\text { clinical } \\
\text { management }\end{array}$ \\
\hline & & $\begin{array}{l}\text { No: } n \\
\text { (\%) } \\
\text { Yes: n } \\
(\%)\end{array}$ \\
\hline
\end{tabular}

\begin{tabular}{|c|c|c|}
\hline $\begin{array}{l}\text { Suspected CD } \\
n=24\end{array}$ & $24(16 \%)$ & $\begin{array}{l}\text { No: } 16 \\
(67 \%)^{*} \\
\text { Yes: } 8 \\
(33 \%)\end{array}$ \\
\hline
\end{tabular}

\begin{tabular}{|c|c|c|c|}
\hline \multirow[t]{5}{*}{$\begin{array}{l}\text { Known CD } \\
n=126\end{array}$} & $\begin{array}{c}\text { Partial bowel } \\
\text { obstruction }\end{array}$ & $53(42 \%)$ & $\begin{array}{l}\text { No: } 15 \\
(28 \%) \\
\text { Yes: } 38 \\
(72 \%)\end{array}$ \\
\hline & $\begin{array}{l}\text { Monitoring } \\
\text { medical } \\
\text { treatment }\end{array}$ & $34(27 \%)$ & $\begin{array}{l}\text { No: } 18 \\
(53 \%) \\
\text { Yes: } 16 \\
(47 \%)\end{array}$ \\
\hline & $\begin{array}{c}\text { Incomplete } \\
\text { ileocolonoscopy }\end{array}$ & $16(13 \%)$ & $\begin{array}{l}\text { No: } 3 \\
(19 \%) \\
\text { Yes: } 13 \\
(81 \%)\end{array}$ \\
\hline & $\begin{array}{l}\text { Small intestine } \\
\text { estension study }\end{array}$ & $15(12 \%)$ & $\begin{array}{l}\text { No: } 4 \\
\text { (27\%) } \\
\text { Yes: } 11 \\
(73 \%)\end{array}$ \\
\hline & $\begin{array}{c}\text { Suspected } \\
\text { complicated CD }\end{array}$ & $8(6 \%)$ & $\begin{array}{l}\text { No: } 1 \\
(12 \%) \\
\text { Yes: } 7 \\
(88 \%)\end{array}$ \\
\hline
\end{tabular}

* Suspected CD vs. known CD, the MRE had less influence on clinical decision making in the group in which the indication was suspected $C D\left(\chi^{2}=9.97, p=0.0016\right)$. 
and biological remission, a change to monotherapy was decided (anti-TNF $\alpha$ only in 2 patients and thiopurines in 1).

The third indication was evaluation of disease activity in patients in whom ileocolonoscopy could not be completed $(n=16,13 \%)$. No inflammatory activity was seen in 3 patients but it was confirmed in the remain 13 patients $(81 \%)$. This was especially useful in those patients with postoperative recurrence in whom endoscopic evaluation of the neo ileum was not possible and in whom anti-TNF $\alpha$ treatment was initiated.

MRE was ordered for extension studies in 15 patients $(12 \%)$. Lesions were found in the jejunum and proximal ileum in 11 patients (73\%), which meant an increase in CD extension. Therapy was intensified in the majority of these patients.

In 8 patients (6\%), the indication was suspected complicated CD. MRE revealed the presence of complications in all but one case. Processes that were not associated with $\mathrm{CD}$ were seen in 2 cases, one haemorrhagic ovarian cyst and one wall abscess associated with infection of an abdominal mesh. Intra-abdominal abscesses secondary to percutaneous drainage and/or surgery were described in 3 patients. In 2 cases, active internal fistulas and/or phlegmons were seen which led to intensification of medical treatment.

Overall, the results of the MRE led to modification of treatment in $83(55.3 \%)$ patients. Eight $(5.3 \%)$ patients started treatment with immunosuppressants, $16(10.7 \%)$ patients with immunosuppressants, $41(27.3 \%)$ started or changed their anti-TNF $\alpha, 15$ patients $(10 \%)$ were ordered to undergo surgery and in 3 patients $(2 \%)$ the MRE led to a change in medical treatment, from combined therapy to monotherapy.

When comparing the two groups; suspected CD vs. known CD, the MRE had less influence on clinical decision making in the group in which the indication was suspected $\mathrm{CD}\left(\chi^{2}=9.97, \mathrm{p}=0.0016\right)$.

\section{DISCUSSION}

MR has played an important role in the management of perianal CD for several years. Most recently, MRE has begun to be used as an imaging technique for the study of CD of the small intestine and colon (7). Classically, the study of the small intestine in CD was performed using SBFT. Different studies have shown the superiority of MRE and CT enterography over SBFT for the study of CD $(3,4)$. The advantages of MRE over CT enterography are the absence of ionising radiation, the ability to perform multiple slices in segments of the intestine which allows low-grade obstructions to be detected and the ability to distinguish between inflammatory activity and fibrosis (8). In the series described, the most frequent indication was the presence of clinical signs of partial bowel obstruction, with the intent of identifying the presence of stenosis due to $\mathrm{CD}$ and to differentiate if the reduction in the lumen was due to the inflammatory activity of the disease or retraction of the intestinal wall due to fibrosis. Fibrotic stenoses appear as segments of the small intestine without peristalsis and with mural thickening of the intestinal wall and narrowing of the intestinal lumen. Performing sequential images with MRE allows information on intestinal motility to be obtained and helps us differentiate between fibrotic stenosis and predominantly inflammatory stenosis. Fibrotic stenoses are typically hypo-intense in T1 and T2 sequences, though they may reveal minimal enhancement with a nonhomogenous distribution without any evidence of oedema or inflammation or signs of hyperaemia (9). These findings, which are suggestive of fibrotic stenosis, allowed us to order surgery directly in a group of patients without intensifying or completing the medical treatment they had been on based on the symptoms of partial bowel obstruction. In all of these cases, the surgical specimens confirmed the predominant role of the inflammatory activity of the fibrosis. Nevertheless, fibrosis coexists with inflammatory activity in many cases, a finding also seen in our series. Three patients required surgery despite intensification of medical treatment due to the detection of inflammatory activity on the MRE. However, the surgical specimens in these patients confirmed the predominant role of fibrosis on the inflammation. Another aspect related to the ability of MRE to determine both intra- and extra-luminal inflammatory activity is the ability to repeat studies, given the absence of ionising radiation, which allows the medical treatment used in CD to be monitored (10). This was the second most frequent indication in our series. MRE is very precise in determining the presence of inflammatory activity (sensitivity $88-98 \%$, specificity $78-100 \%$ ) $(5,11)$. In addition, MRE allows the level of CD severity to be determined, demonstrating a good correlation with endoscopic findings, especially when the intestinal lumen has been sufficiently distended $(12,13)$. Recently, a radiological index of disease activity, the Magnetic Resonance Index of Activity (MRIA), has been described based on the quantitative changes observed on MRE. This correlates with the severity of the endoscopic lesions and with the presence of oedema, ulcers, size of lymph nodes and the presence of pseudopolyps $(14,15)$. In our series, we evaluate CD activity based on wall thickening, the presence of ulcers, increase in vascularisation, mesenteric inflammation and the presence of reactive lymphadenopathies (16). The information obtained on MRE was useful in scaling medical treatment in almost $50 \%$ of patients in whom it was performed for the purpose of monitoring medical treatment. In many cases, it led to starting treatment with biological therapy, immunosuppressants or even surgery in one case. In addition, MRE also allowed 3 patients on combined therapy (anti-TNF $\alpha+$ immunosuppressants) to go on monotherapy as they were found to be in clinical and biological remission once the absence of radiological activity in the small intestine was confirmed. MRE also allows us to explore tracts of the ileum in patients in whom ileocolonoscopy was incomplete. This was especially relevant in patients who underwent the study to look for the presence of postoperative recurrence of CD. In the majority of instances, the MRE revealed severe lesions that led to starting treatment with biological therapy. MRE has shown a good correlation with the Rutgeerts endoscopic score in previous 
studies (17) and it allows for differentiation between mild and severe lesions with a K coefficient greater than 0.8 .

Current recommendations claim for a radiological study that evaluates the extent of $\mathrm{CD}$ in the small intestine (jejunum and ileum) following the initial diagnosis of $\mathrm{CD}$ (6). MRE is very precise in determining the location and extension of the inflammatory lesions (sensitivity $74 \%$, specificity $91 \%$ ) in CD (5), which is very close to the precision demonstrated by CT enterography (18) and greater than the precision of ultrasound for locations in the jejunum and proximal ileum (19). In our series, the majority of the patients in whom an extension study was performed using MRE, disease activity was found in the jejunum and proximal ileum which led to a change in the therapeutic management of these patients due to having extensive disease.

MRE also played an important role in identifying complications, not only the stenoses mentioned above, but also the presence of penetrating complications (intra-abdominal abscesses). It should be noted that when faced with these types of complications, ultrasound and/or CT was chosen due to the greater availability of these studies on an emergency basis. But the risk of overexposure to ionizing radiation in these patients so you should try to avoid CT (20). MRE has a good sensitivity level of 86\% (95\%CI; 79-91\%) and specificity of $93 \%(95 \% \mathrm{CI} ; 88-97 \%)$ in this clinical setting (5). One aspect that should be pointed out is that MRE allowed for a differential diagnosis to be made between other extra-intestinal processes that had been clinically confused with complicated CD. In our case, these were a haemorrhagic ovarian cyst and an abdominal wall abscess caused by a complicated surgical mesh.

Finally, MRE was used for diagnostic confirmation when $\mathrm{CD}$ was suspected. In these situation, MRE showed a sensitivity of $78 \%(95 \% \mathrm{CI} ; 67-84 \%)$ and a specificity of $85 \%$ (95\%CI; 76-84\%) (5). In our series, this indication was less worthwhile than the indication was the follow up of known CD patient. On the majority of occasions, MRE only confirmed the findings of other studies or tests performed on the patients. This is explained by the fact that the diagnosis of CD is based on clinical, laboratory, endoscopic, histopathology and radiological findings and no single study is diagnostic.

In general, the use of MRE in our series helped on the clinical decision in more than half of patients, especially with regards to decisions related to the use of biological therapies and the indication for surgery.

\section{ACKNOWLEDGEMENTS}

Medical writing assistance was supported by Abbott Laboratories.

\section{REFERENCES}

1. Freeman HJ. Natural history and clinical behavior of Crohn's disease extending beyond two decades. J Clin Gastroenterol 2003;37:216-9.
2. Zappa M, Stefanescu C, Cazals-Hatem D, Bretagnol F, Deschamps L, Attar A, et al. Which magnetic resonance imaging findings accurately evaluate inflammation in small bowel Crohn's disease? A retrospective comparison with surgical pathologic analysis. Inflamm Bowel Dis 2011;17:984-93

3. Triester SL, Leighton JA, Leontiadis GI, Gurudu SR, Fleischer DE, Hara AK, et al. A meta-analysis of the yield of capsule endoscopy compared to other diagnostic modalities in patients with non-stricturing small bowel Crohn's disease. Am J Gastroenterol 2006;101:954-64.

4. Hara AK, Leighton JA, Heigh RI, Sharma VK, Silva AC, De Petris G, et al. Crohn disease of the small bowel: preliminary comparison among CT enterography, capsule endoscopy, small-bowel follow-through, and ileoscopy. Radiology 2006;238:128-34.

5. Panes J, Bouzas R, Chaparro M, García-Sánchez V, Gisbert JP, Martínez de Guereñu B, et al. Systematic review: the use of ultrasonography, computed tomography and magnetic resonance imaging for the diagnosis, assessment of activity and abdominal complications of Crohn's disease. Aliment Pharmacol Ther 2011;34:125-45.

6. Van Assche G, Dignass A, Panes J, Beaugerie L, Karagiannis J, Allez $\mathrm{M}$, et al. The second European evidence-based Consensus on the diagnosis and management of Crohn's disease: Definitions and diagnosis. J Crohns Colitis 2010;4:7-27.

7. Shrot S, Konen E, Hertz M, Amitai MM. Magnetic resonance enterography: 4 years experience in a tertiary medical center. Isr Med Assoc J 2011;13:172-7.

8. Fletcher JG, Fidler JL, Bruining DH, Huprich JE. New concepts in intestinal imaging for inflammatory bowel diseases. Gastroenterology 2011;140:1795-806.

9. Siddiki HA, Fidler JL, Fletcher JG, Burton SS, Huprich JE, Hough DM, et al. Prospective comparison of state-of-the-art MR enterography and CT enterography in small-bowel Crohn's disease. AJR Am J Roentgenol 2009;193:113-21.

10. Mendoza JL. Ionizing radiation in Crohn s disease patients. Rev Esp Enferm Dig 2012;104(9):449-51.

11. Mazziotti S, Ascenti G, Scribano E, Gaeta M, Pandolfo A, Bombaci $F$, et al. Guide to magnetic resonance in Crohn's disease: from common findings to the more rare complicances. Inflamm Bowel Dis 2011;17:1209-22.

12. Hyun SB, Kitazume Y, Nagahori M, Toriihara A, Fujii T, Tsuchiya K, et al. Magnetic resonance enterocolonography is useful for simultaneous evaluation of small and large intestinal lesions in Crohn's disease. Inflamm Bowel Dis 2011;17:1063-72.

13. Oussalah A, Laurent V, Bruot O, Bressenot A, Bigard MA, Régent D, et al. Diffusion-weighted magnetic resonance without bowel preparation for detecting colonic inflammation in inflammatory bowel disease. Gut 2010;59:1056-65

14. Rimola J, Ordas I, Rodriguez S, García-Bosch O, Aceituno M, Llach $\mathrm{J}$, et al. Magnetic resonance imaging for evaluation of Crohn's disease: validation of parameters of severity and quantitative index of activity. Inflamm Bowel Dis 2011;17:1759-68.

15. Rimola J, Rodriguez S, Garcia-Bosch O, Ordás I, Ayala E, Aceituno $\mathrm{M}$, et al. Magnetic resonance for assessment of disease activity and severity in ileocolonic Crohn's disease. Gut 2009;58:1113-20.

16. Masselli G, Casciani E, Polettini E, Lanciotti S, Bertini L, Gualdi G. Assessment of Crohn's disease in the small bowel: Prospective comparison of magnetic resonance enteroclysis with conventional enteroclysis. Eur Radiol 2006;16:2817-27.

17. Sailer J, Peloschek P, Reinisch W, Vogelsang H, Turetschek K, Schima W. Anastomotic recurrence of Crohn's disease after ileocolic resection: comparison of MR enteroclysis with endoscopy. Eur Radiol 2008;18:2512-21.

18. Fiorino G, Bonifacio C, Peyrin-Biroulet L, Minuti F, Repici A, Spinelli $\mathrm{A}$, et al. Prospective comparison of computed tomography enterography and magnetic resonance enterography for assessment of disease activity and complications in ileocolonic Crohn's disease. Inflamm Bowel Dis 2011:17:1073-80.

19. Pascu M, Roznowski AB, Muller HP, Adler A, Wiedenmann B, Dignass AU. Clinical relevance of transabdominal ultrasonography and magnetic resonance imaging in patients with inflammatory bowel disease of the terminal ileum and large bowel. Inflamm Bowel Dis 2004:10:373-82.

20. Ciáurriz A, Fraile M, León H, Vicuña M, Miquélez S, Úriz J, et al. Ionizing radiation in Crohn $\mathrm{s}$ disease patients: Estimation and associated factors. Rev Esp Enferm Dig 2012;104(9):452-7. 